Daisuke Takahashi · Masanori Kohda

\title{
Courtship in fast water currents by a male stream goby (Rhinogobius brunneus) communicates the parental quality honestly
}

Published online: 21 November 2003

(C) Springer-Verlag 2003

\section{Behav Ecol Sociobiol (2003) DOI 10.1007/s00265- 003-0693-1}

Fig. 1 contained incorrect symbols. The correct version is given below.
The online version of the original article can be found at http://dx.doi.org/10.1007/s00265-003-0693-1

\footnotetext{
D. Takahashi $(\bullet) \cdot$ M. Kohda

Department of Bio- and Geosciences, Graduate School of Science, Osaka City University,

Sumiyoshi-ku, Osaka 558-8585, Japan

e-mail: taka@terra.zool.kyoto-u.ac.jp

Tel.: +81-75-7534077

Fax: +81-75-75344100

Present address:

D. Takahashi, Laboratory of Animal Ecology,

Department of Zoology, Graduate School of Science,

Kyoto University,

Kyoto 606-8502, Japan
}

A

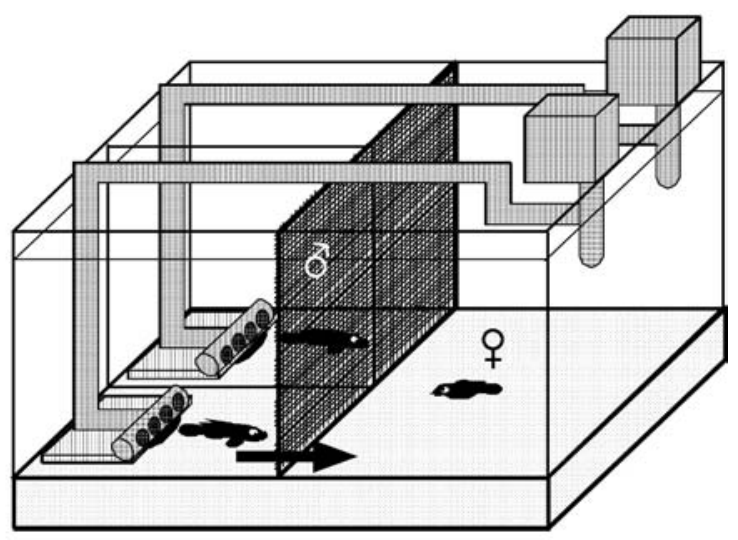

B

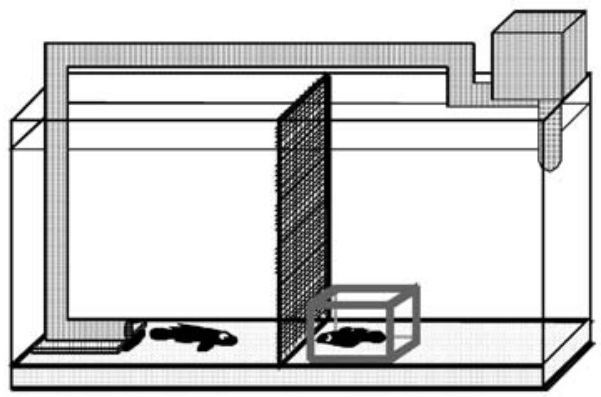

Fig. 1 Diagram of the tanks used in experiments of female stream goby (Rhinogobius brunneus) choice (A: tank A) and measuring maximum water velocity of water currents in which male can court (B: tank B). Pumps and PVC pipes are shown. The arrow indicates direction of water current. Two male compartments in tank A are actually bordered by an opaque board 